\title{
Increases in statin eligibility to reduce cardiovascular risk according to the 2013 ACC/AHA cholesterol guidelines in the Africa Middle East region: a sub-analysis of the Africa Middle East Cardiovascular Epidemiological (ACE) study
}

Omar Hamoui ${ }^{1 *}$ (D) Mohamed I. Omar ${ }^{2}$, Frederick J. Raal ${ }^{3}$, Wafa Rashed ${ }^{4}$, Abdoul Kane ${ }^{5}$, Mohamed Alami ${ }^{6}$, Paula Abreu', Walid Mashhoud ${ }^{8}$ and Alawi A. Alsheikh-Ali ${ }^{9}$

\begin{abstract}
Background: With development of cholesterol management guidelines by the American College of Cardiology/ American Heart Association (ACC/AHA), more individuals at risk of cardiovascular disease may be eligible for statin therapy. It is not known how this affects statin eligibility in the Africa and Middle East Region.

Methods: Data were used from the Africa Middle East Cardiovascular Epidemiological (ACE) study. The percentage of subjects eligible for statins per the ACC/AHA 2013 cholesterol guidelines and the 2002 National Cholesterol Education Program-Adult Treatment Panel (NCEP-ATP III) recommendations were compared. Analyses were carried out according to age, gender, community (urban/rural), and country income categories based on World Bank definitions.

Results: According to the ACC/AHA recommendations, 1695 out of 4378 subjects (39\%; 95\% confidence interval [CI], 37-40\%) satisfied statin eligibility criteria vs. 1043/4378 (24\%; 95\% Cl, 23-25\%) per NCEP-ATP recommendations, representing a $63 \%$ increase in statin eligibility. Consistent increases in eligibility for statin therapy were seen according to the ACC/AHA vs. NCEP-ATP guidelines across sub-groups of age, gender, community, and country income. Notable increases for statin eligibility according to ACC/AHA vs. NCEP-ATP were seen, respectively, in subjects aged $\geq 65$ years ( $86 \%$ vs. $39 \%$ ), in males ( $46 \%$ vs. $25 \%$ ), in low-income countries (28\% vs. $14 \%$ ), and rural communities (37\% vs. $19 \%)$.
\end{abstract}

Conclusion: An increase in statin eligibility was seen applying ACC/AHA cholesterol guidelines compared with previous NCEP-ATP recommendations in the Africa Middle East region. The economic consequences of these guideline recommendations will need further research.

Trial registration: The ACE trial is registered under NCT01243138.

Keywords: Africa Middle East region, Cholesterol guidelines, Lipid-lowering therapy, Income, The Africa and Middle East Cardiovascular Epidemiological (ACE) study, Statin therapy

\footnotetext{
* Correspondence: ohamoui@gmail.com

${ }^{1}$ Cardiovascular Diseases, Clemenceau Medical Center, Beirut, Lebanon

Full list of author information is available at the end of the article
}

(c) The Author(s). 2019 Open Access This article is distributed under the terms of the Creative Commons Attribution 4.0 International License (http://creativecommons.org/licenses/by/4.0/), which permits unrestricted use, distribution, and reproduction in any medium, provided you give appropriate credit to the original author(s) and the source, provide a link to the Creative Commons license, and indicate if changes were made. The Creative Commons Public Domain Dedication waiver (http://creativecommons.org/publicdomain/zero/1.0/) applies to the data made available in this article, unless otherwise stated. 


\section{Background}

The use of lipid-lowering therapy, in particular statins, has been shown to reduce cardiovascular morbidity and mortality in numerous, multinational, randomized, double-blind clinical trials and meta-analyses [1-5]. Primary prevention trials in patients with cardiovascular risk factors have also demonstrated positive results with statin use, although with some variability in the magnitude of benefit [4, 6-8]. It is expected that increased use of lipid-lowering therapy in high-risk patients will result in wider benefits with short- and long-term use, leading to prevention of cardiovascular disease and the associated morbidity and mortality [9], sustaining a trend observed over the past few decades [10]. The socioeconomic implications of such trends are appealing, although this comes at a higher direct cost of prescription medications. Countries with adequate financial resources are better prepared to afford the short-term costs of prescription medications in order to recover the long-term benefits of reducing the morbidity and mortality associated with cardiovascular disease. Developing countries, on the other hand, with more limited financial resources, may be challenged to provide the medications and healthcare needed to meet recommendations for management of cardiovascular disease [11].

Developing countries share a large burden of the worldwide cardiovascular epidemic [12, 13]. Dyslipidemia constitutes a major risk factor for cardiovascular events in the Africa Middle East region [14-18]; for example, dyslipidemia is associated with the highest overall population-attributable risk among conventional risk factors for ischemic heart disease, according to the INTERHEART study, which included patients from Africa and the Middle East $[12,16]$. Therefore, data on statin eligibility from developing countries are essential for adequate planning at the societal level.

Utilizing data from a study of cardiovascular risk factors across the Africa and Middle East region [15], the present study investigates the impact that 2013 ACC/AHA blood cholesterol guidelines [19] have on patient eligibility for statin use in this cohort of outpatients from the Africa Middle East region in comparison with the established National Cholesterol Education Program Adult Treatment Panel III (NCEP ATP III) blood cholesterol guidelines [20].

\section{Methods}

Data collected for the Africa Middle East Cardiovascular Epidemiological (ACE) study [15] were analyzed for this sub-analysis. The ACE study evaluated cardiovascular risk factors of ambulatory patients attending general practice clinics in urban and rural areas of 14 countries in the Africa Middle East region. This multi-country, multicenter cross-sectional study was conducted between July
2011 and April 2012 [15]. Site selection was based on whether the centers had previous experience in clinical trials and whether ethical oversight and infrastructure were present for conducting clinical research [15].

Adult outpatients aged $\geq 18$ years and who provided informed consent, were eligible for inclusion in the ACE study and for this sub-analysis. Every fifth outpatient attending the clinic for any reason was included in the study. Patients who were pregnant, lactating, or presented with a life-threatening illness were not eligible. The primary observation of the ACE study was percentage of outpatients with major cardiovascular risk factors, including dyslipidemia, hypertension, diabetes, obesity, and smoking [15]. Countries were selected based on the availability of epidemiologic data.

The site physician was responsible for the study evaluations, including history taking, physical examination, and laboratory tests. Laboratory evaluations were carried out during a single visit; a second visit was allowed only for non-fasting outpatients who returned to provide a fasting blood sample for the laboratory investigations. Ethics, institutional review board, and appropriate regulatory body approvals were obtained by all sites participating in the study. The primary results of the study have been previously reported [15]. The ACE study is registered on ClinicalTrials.gov identifier (NCT01243138).

The objective of the current sub-analysis was to estimate the percentage of outpatients in the ACE study population who would have been eligible for statin therapy according to the 2013 ACC/AHA guidelines [19] compared with the percentage who met eligibility criteria per the NCEP ATP III guidelines at enrollment [20]. The risk factors identified in the ACE study were used to ascertain the eligibility for statin therapy according to the above guidelines.

\section{Definitions of risk factors}

Patients were identified as having dyslipidemia if they had at least one of: high total cholesterol, high low-density lipoprotein cholesterol (LDL-C), high triglycerides, low high-density lipoprotein cholesterol (HDL-C), or were on lipid-lowering/statin medications. High total cholesterol was defined as $(\geq 240 \mathrm{mg} / \mathrm{dL})$. Elevated $\mathrm{LDL}-\mathrm{C}$ was defined as $\geq 100 \mathrm{mg} / \mathrm{dL}, \geq 130 \mathrm{mg} / \mathrm{dL}$, or $\geq 160 \mathrm{mg} / \mathrm{dL}$ in outpatients with high-, moderate-, or low cardiovascular risk, respectively, according to NCEP ATP III 2002 guidelines [20], which were contemporary and used in clinical practice at the time of the ACE study [15]. Low HDL-C level was defined as $<40 \mathrm{mg} / \mathrm{dL}$ in males and $<50 \mathrm{mg} / \mathrm{dL}$ in females. High triglyceride level was defined as $\geq 200 \mathrm{mg} / \mathrm{dL}$. Additional risk factors assessed to determine cardiovascular risk status were: smoking; hypertension or on antihypertensive medication; low HDL-C $(<40 \mathrm{mg} / \mathrm{dL})$; family history of premature 
coronary heart disease (CHD), defined as CHD in male first degree relative aged $<55$ years, or CHD in female first degree relative aged < 65 years; and age (men $\geq 45$ years; women $\geq 55$ years). Diabetes was regarded as a CHD risk equivalent [20].

Hypertension was recorded in outpatients who were receiving anti-hypertensive medications or had a blood pressure (BP) measurement $\geq 140 / 90 \mathrm{mmHg}$, according to the European Society of Cardiology (ESC) guidelines (2007) [21], contemporary to the ACE study [15]. Diabetes mellitus was defined based on a fasting blood glucose measurement $\geq 126 \mathrm{mg} / \mathrm{dL} \quad(7 \mathrm{mmol} / \mathrm{L})$, per American Diabetes Association 2010 criteria [22] or the use of hypoglycemic agents. Former smokers were recorded as those who were not current smokers but had a history of smoking. The use of anti-hypertensive, lipid-lowering, and hypoglycemic therapy was also documented.

\section{Eligibility per ACC/AHA and NCEP ATP III}

Patients were considered eligible for statin therapy per 2013 ACC/AHA guidelines if they had one of the following criteria: (1) clinical atherosclerotic cardiovascular disease (ASCVD); (2) primary elevations of LDL-C $\geq 190$ $\mathrm{mg} / \mathrm{dL}$; (3) diabetes mellitus, with age $40-75$ years, and with LDL-C $70-189 \mathrm{mg} / \mathrm{dL}$ in the absence of clinical ASCVD; or (4) LDL-C 70-189 mg/dL, with age 40-75 years, and with estimated 10-year ASCVD risk $\geq 7.5 \%$ in the absence of clinical ASCVD or diabetes mellitus. Outpatients aged $40-75$ years, but without clinical ASCVD or diabetes, LDL-C $70-189 \mathrm{mg} / \mathrm{dL}$, and with estimated 10-year ASCVD risk $\geq 5 \%$, were also assessed. The 10-year risk for ASCVD was evaluated by using the Pooled Cohort Equations calculator [19].

Patients were considered eligible for statins per 2002 NCEP ATP III guidelines if they had one of the following: (A) 0-1 cardiovascular risk factors (per NCEP ATP III criteria, as outlined above) plus LDL-C $\geq 190 \mathrm{mg} / \mathrm{dL}$; (B) 2 or more cardiovascular risk factors plus LDL-C $\geq 130 \mathrm{mg} / \mathrm{dL}$; or (C) known CHD, transient ischemic attack, stroke, peripheral arterial disease, or diabetes plus LDL-C $\geq 100 \mathrm{mg} / \mathrm{dL}$ [20].

\section{Definitions of income status}

The World Bank Atlas method was used to define the national income categories of the participating countries [23]. A country was classified as low income (LI) when the Gross National Income (GNI) per capita (US\$) was $\$ 1005$ or less in 2010. Countries with a GNI per capita of \$1006 to \$3975 were considered lower-middle income (LMI). Countries with a GNI per capita of $\$ 3976$ to $\$ 12,275$ were defined as upper-middle income (UMI), and countries with a GNI per capita of $\$ 12,276$ or more were considered high income (HI). Income classification by country was as follows: low income - Kenya; lower-middle income - Cameroon, Ghana, Egypt, Nigeria, and Senegal; upper-middle income - Algeria, Jordan, Lebanon, Tunisia, and South Africa; high income - Kuwait, Saudi Arabia, and the United Arab Emirates.

\section{Definition of community}

Rural areas were defined as areas greater than $50 \mathrm{~km}$ away from an urban area and without easy transportation [24].

\section{Statistical analysis}

The number and percentage of outpatients for dichotomous variables, such as prevalence and number of outpatients who were eligible for lipid-lowering/statin therapy according to 2002 NCEP ATP III and 2013 ACC/AHA guidelines, are presented. Two-sided exact (Wilson Scores test) 95\% confidence intervals (CIs) were used to calculate the percentage. Descriptive statistics, which included sample size, mean, standard deviation, median, minimum, and maximum, were used to summarize the continuous data (e.g., lipid parameters, BP parameters, and glucose). Outpatients were categorized by community (rural or urban), income level (LI, LMI, UMI, HI), gender and/or age range (young $=$ aged $18-44$ years, middle aged $=45-64$ years, elderly $=\geq 65$ years $)$.

The full analysis set population served as the basis for all efficacy summaries and analyses, which were primarily descriptive in nature.

\section{Results}

\section{Outpatient characteristics}

The ACE study reported the prevalence of cardiovascular risk factors in 4378 outpatients [15]. The study population included $52 \%$ who were female and $31 \%$ from rural communities across the Africa Middle East region [15].

Of the total ACE study population, 197 (5\%) outpatients had ASCVD, 136 (3\%) had LDL-C $\geq 190 \mathrm{mg} / \mathrm{dL}$; $510(12 \%)$ had diabetes mellitus with no ASCVD and were aged $40-75$ years with LDL-C $70-189 \mathrm{mg} / \mathrm{dL}$; and 852 (20\%) had an estimated 10-year ASCVD risk $\geq 7.5 \%$ per the Pooled Cohort Equation with no ASCVD or diabetes and aged $40-75$ years with LDL-C $70-189 \mathrm{mg} / \mathrm{dL}$ (Table 1). Following the NCEP ATP III guidelines, 104 (2\%) outpatients had $0-1$ risk factor with LDL-C $\geq 190$ $\mathrm{mg} / \mathrm{dL} ; 566(13 \%)$ had 2 or more risk factors with LDL-C $\geq 130 \mathrm{mg} / \mathrm{dL}$; and 373 (9\%) had ASCVD or diabetes and LDL-C $\geq 100 \mathrm{mg} / \mathrm{dL}$ (Table 1). Overall, 1169 outpatients (27\%) aged 40-75 years, but without diabetes or clinical ASCVD, had 10-year ASCVD risk $\geq 5 \%$ and LDL-C $70-189 \mathrm{mg} / \mathrm{dL}$. Therefore, if $\mathrm{a} \geq 5 \%$ ASCVD threshold was applied for statin eligibility in this 
Table 1 Statin-eligible groups by 2013 ACC/AHA and NCEP ATP III guidelines

\begin{tabular}{|c|c|}
\hline Statin-eligible group & $n(\%)$ \\
\hline \multicolumn{2}{|l|}{ per 2013 ACC/AHA guidelines } \\
\hline Aged $\geq 21$ y with ASCVD & $197(4.5)$ \\
\hline Aged $\geq 21$ y with untreated LDL-C $\geq 190 \mathrm{mg} / \mathrm{dL}$ & $136(3.1)$ \\
\hline $\begin{array}{l}\text { Aged } 40-75 \text { y with LDL-C } 70-189 \mathrm{mg} / \mathrm{dL} \\
\text { and DM without ASCVD }\end{array}$ & $510(11.6)$ \\
\hline $\begin{array}{l}\text { Aged } 40-75 \text { y with } L D L-C 70-189 \mathrm{mg} / \mathrm{dL} \\
\text { without ASCVD or DM and ASCVD risk } \geq 7.5 \%\end{array}$ & $852(19.5)$ \\
\hline Total eligible & $1695(39.0)$ \\
\hline \multicolumn{2}{|l|}{ per 2002 NCEP ATP III guidelines } \\
\hline $0-1$ risk factor and $\mathrm{LDL}-\mathrm{C} \geq 190 \mathrm{mg} / \mathrm{dL}$ & $104(2.4)$ \\
\hline$\geq 2$ risk factors and $\mathrm{LDL}-\mathrm{C} \geq 130 \mathrm{mg} / \mathrm{dL}$ & $566(12.9)$ \\
\hline CHD, TIA, stroke, PAD, DM, and LDL-C $\geq 100 \mathrm{mg} / \mathrm{dL}$ & $373(8.5)$ \\
\hline Total eligible & $1043(24.0)$ \\
\hline
\end{tabular}

population, rather than the $\geq 7.5 \%$ level, the total proportion of statin-eligible patients increases from 39\% $(1695 / 4378)$ to $46 \%(2012 / 4378)$.

\section{Eligibility for statin therapy according to ACC/AHA or NCEP ATP III guidelines}

A total of 1043 (24\% [95\% CI: 23, 25\%]) outpatients were eligible for statin therapy per the NCEP ATP III guidelines and 1695 (39\% [95\% CI: 37, 40\%]) were eligible according to 2013 ACC/AHA guidelines (Fig. 1). Most of the outpatients eligible for statin therapy per 2013 ACC/ AHA guidelines qualified based on their calculated 10 -year risk of ASCVD $\geq 7.5 \%$, in the absence of clinical ASCVD or diabetes mellitus (20\%); the remainder qualified based on having diabetes mellitus (12\%), clinical ASCVD (5\%), or primary elevations of LDL-C (3\%) (Table 1).

Overall statin eligibility increased by 63\% [(eligible per ACC/AHA) - (eligible per NCEP ATP III)/(eligible per NCEP ATP III $) \times 100=(1695-1043 / 1043) \times 100]$ according to the $2013 \mathrm{ACC} / \mathrm{AHA}$ guidelines compared with the earlier 2002 NCEP ATP III guidelines (Table 1; Fig. 1). This increase in eligibility for statin therapy was consistent across subgroups, namely male or female, urban or rural communities, age group (younger, middle-aged, older), and country income level (Fig. 1). When data were analyzed by age and gender, a similar pattern was seen across all age cohorts, with the exception of a slight reduction in young males (18-44 years) (Fig. 1c). Large increases in statin eligibility were seen for both elderly male and female outpatients, and in particular for male outpatients aged $\geq 65$ years (+151\% with NCEP vs. ACC/AHA) (Fig. 1c).
Furthermore, according to the 2013 AHA/ACC guidelines, when ASCVD risk was set at $\geq 7.5 \%$, the proportion of statin eligible patients showed a gender difference in the middle aged bracket (45-64 years), with a higher eligibility among men vs. women (70\% [95\% CI: 66.7, 72.7\%) vs. $44 \%$ [95\% CI: 40.9, 47.2\%]) (Fig. 1c and d). According to the NCEP ATP III guidelines, this difference was not apparent, as the same proportion of male and female outpatients were eligible for statin therapy (33\%) (Fig. 1c and d).

There were consistent increases in eligibility for statin therapy according to the 2013 ACC/AHA guidelines across the participating countries, ranging from a $27 \%$ increase in Egypt to 100\% increase in eligibility in Kenya (Fig. 2). Significant increases in eligibility for statin therapy with 2013 ACC/AHA vs. NCEP ATP III guidelines, respectively, were also particularly noted among males ( $46 \%$ vs. $25 \%$ ), in rural communities (37\% vs. $19 \%$ ), the elderly (aged $\geq 65$ years) ( $86 \%$ vs. $39 \%$ ), and low income countries (28\% vs. $14 \%)$ (Fig. 1$)$.

Use of statin therapy according to NCEP ATP III guidelines Among outpatients eligible for statin therapy per NCEP ATP III guidelines [20], the use of these medications was low in the overall cohort (27\%) (Fig. 3), including those with prior cardiovascular disease or risk equivalent (Group C, 32\%; Fig. 3a). The lack of statin use in eligible outpatients was a consistent finding across gender, community (urban and rural), age groups, and by country income level. The proportion of statin-eligible outpatients prescribed medications was particularly low among women $(23 \%)$, and those in rural communities $(16 \%)$ or in lower-income (LI/LMI) countries (8\%) (Fig. 3).

\section{Discussion}

In a relatively young, ambulatory population attending general practice clinics in the Africa Middle East region, we observed a significant increase in eligibility for statin treatment when the 2013 cholesterol guidelines from ACC/AHA [19] were applied compared with the 2002 NCEP ATP III criteria [20]. Overall, there was a relative increase in statin eligibility of 63\% (from 24 to $39 \%$ ) in the overall study cohort, and an increase was observed in each of the 14 countries, ranging from a relative increase of $27 \%$ in Egypt to $100 \%$ in Kenya. This pattern was consistent across age groups, gender, community type, and national income levels. If the $\geq 5 \%$ ASCVD threshold was applied for statin eligibility, rather than the $\geq 7.5 \%$ level, the proportion of statin-eligible patients from the total study population increased even more, from 39 to $46 \%$, with the highest proportion of patients (aged 40-75 years with LDL-C $70-189 \mathrm{mg} / \mathrm{dL}$ ) being eligible based on predicted ASCVD risk $\geq 5 \%$, but no diabetes or clinical ASCVD. This represents $7.2 \%$ of 


\section{a Overall and by gender}

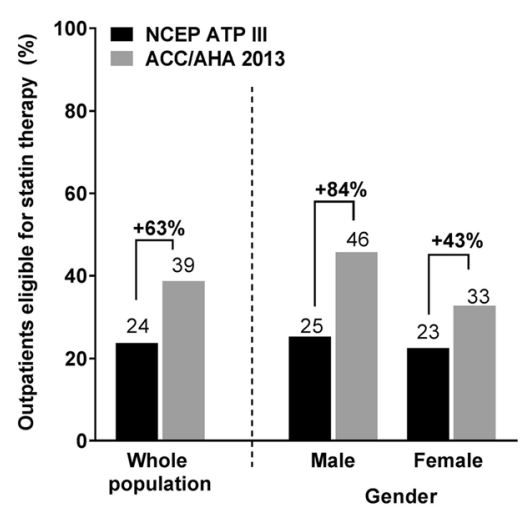

C Male, by age cohort

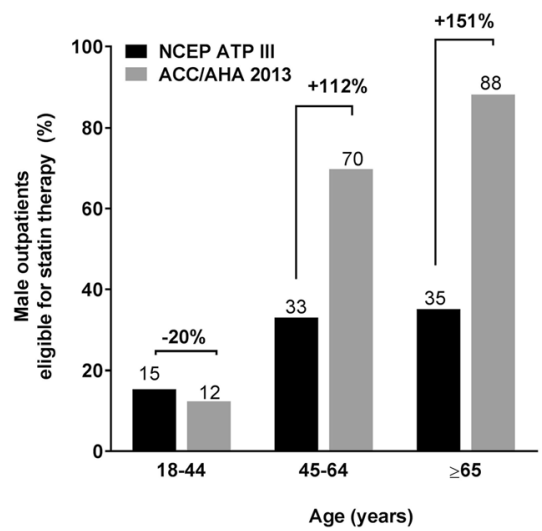

e By community

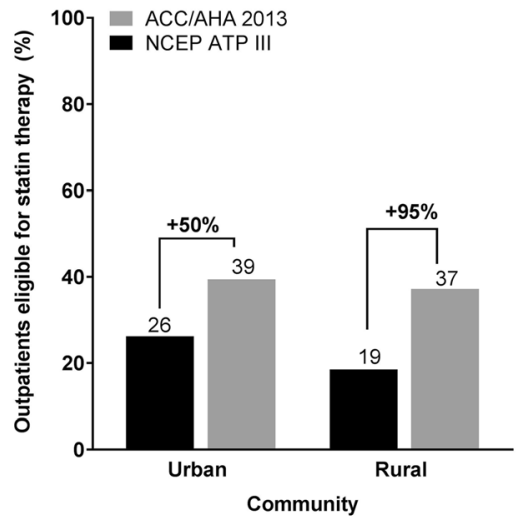

b By age

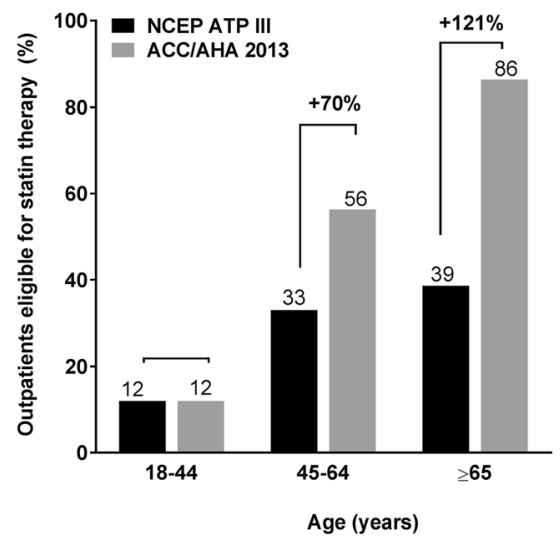

d Female, by age cohort

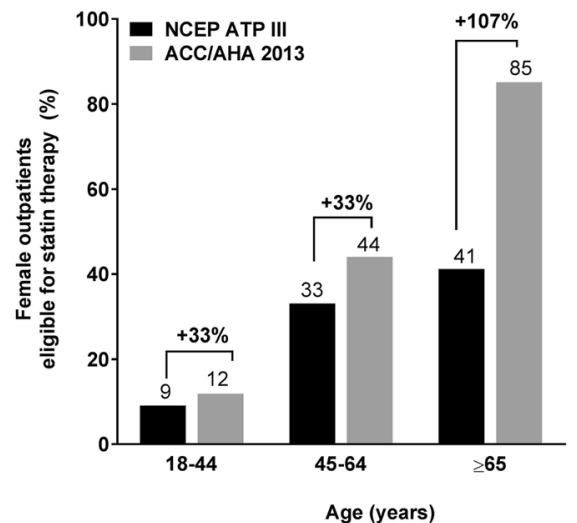

f By income status

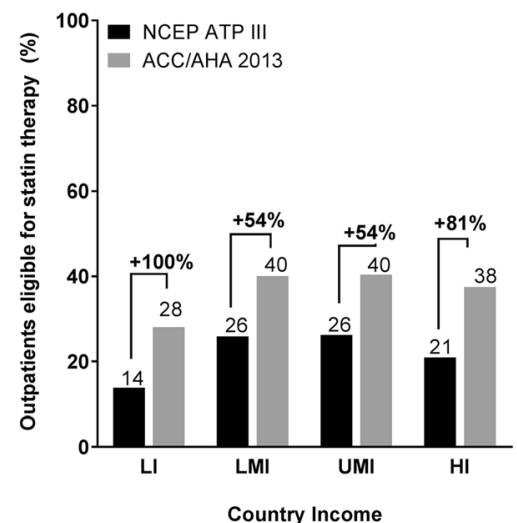

Fig. 1 Statin eligibility by subgroups. ACC/AHA American College of Cardiology/American Heart Association, NCEP ATP III National Cholesterol Education Program Adult Treatment Panel III, HI high-income country, LI lower income country, LMI lower-middle income country, UMl upper-middle income country

patients who had a predicted ASCVD $\geq 5$ but $<7.5 \%$, who may be eligible for statin therapy, based on the presence of other cardiovascular risk factors contributing to the predicted risk, for example calcium scoring, ankle brachial index, or family history, etc. As noted above, more than one-third (39\%) of the cohort had cardiovascular risk status making them eligible for statin therapy when the 2013 ACC/AHA statin therapy recommendations were applied. These individuals would be at high risk of developing future cardiovascular events, and would 


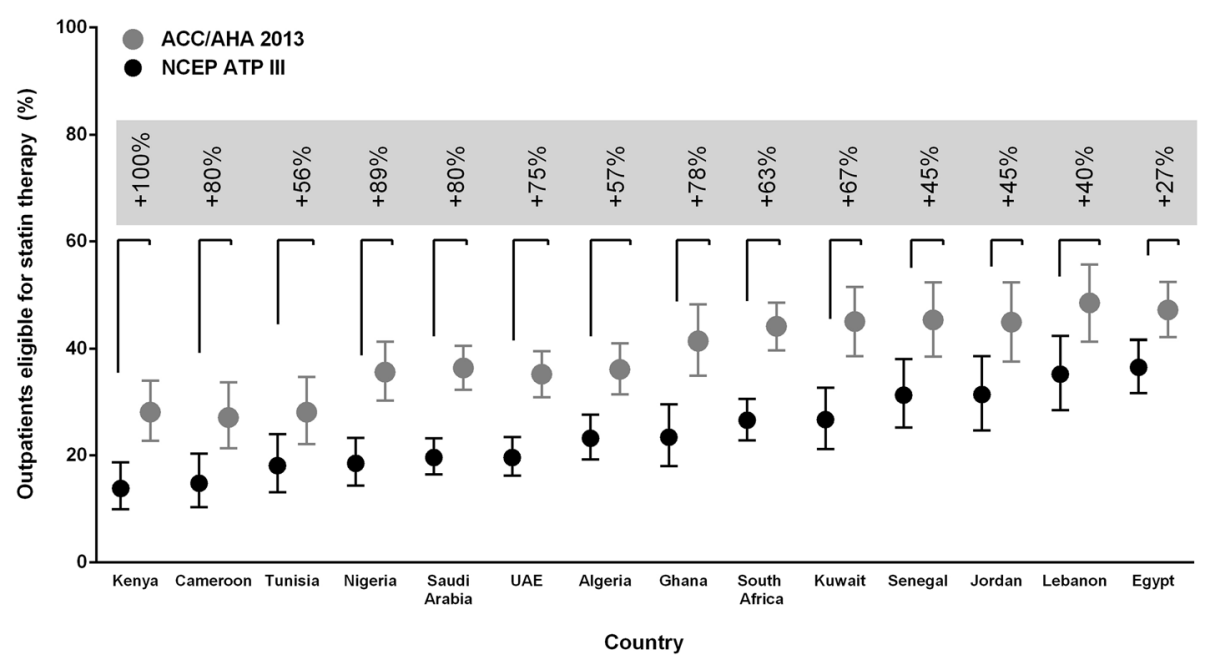

Fig. 2 Statin eligibility by participating country: NCEP ATP III and the 2013 ACC/AHA criteria. The vertical lines represent 95\% confidence intervals. The percentages at the top of the figure (gray boxes) represent the relative increase in the proportion of eligible patients per country. ACC/AHA American College of Cardiology/American Heart Association, NCEP ATP III National Cholesterol Education Program Adult Treatment Panel III, UAE United Arab Emirates

benefit significantly from intensive lifestyle management and statin therapy. This is supported by meta-analyses which have demonstrated that patients across different ethnicities, and at varying degrees of cardiovascular risk, benefit from statin therapy $[3,4,25,26]$, although with greater absolute benefits in patients at greater baseline risk [26].

The present findings are particularly relevant given the current burden and projected increase of cardiovascular disease morbidity and mortality in the developing world in general and within the Africa Middle East region in particular [27]. Developing countries are estimated to account for $85 \%$ of the global burden of cardiovascular disease [12, 13]. Conventional modifiable risk factors account for a large proportion of the cardiovascular disease burden in the Africa and the Middle East region $[12,16]$. Notably, dyslipidemic factors are estimated to account for approximately 57 and $62 \%$ of the population attributable risk of myocardial infarction in the Middle East and Africa, respectively [12, 16]. In this context, assessing the proportion of adults eligible for statin therapy based on the cholesterol guidelines is relevant to healthcare providers and policy makers in their efforts to combat cardiovascular disease in these regions.

Increasing the number of outpatients eligible for statin therapy would have economic and system-wide implications. This is particularly true, as the most notable increase in statin eligibility in the present study was observed in lower-income countries with fewer resources, and in rural communities with potentially less-developed systems. Adherence to guidelines and the resulting increased eligibility for lipid-lowering therapy would require a significant increase in healthcare resources, as prescription drugs constitute a major element of healthcare costs of cardiovascular prevention. Judicious planning of healthcare resource utilization, improving access to care in rural communities, and coordinated efforts to lower prescription drug costs will be needed to meet the expected increase in eligible outpatients. The estimates provided by the present analysis should inform such efforts.

Approximately half of the outpatients eligible for statins per 2013 ACC/AHA guidelines qualified based on their calculated 10-year risk of ASCVD of $\geq 7.5 \%$ in the absence of clinical ASCVD or diabetes mellitus. These observations have important implications for the Africa Middle East region. The cost-effectiveness of statins in the primary prevention of cardiovascular disease is variable and is dependent on the estimated absolute risk of disease as well as the cost of prescription drugs. Both of these variables are not well-defined in the Africa Middle East region. Cost of drug data are not readily available and, given the variable cost structure and value of money, cost-effectiveness estimates from developed countries (United States or Europe) may not be directly applicable to the Africa Middle East region. Importantly, the risk model used to estimate risk of disease, upon which eligibility is reliant, has not been independently validated in cohorts from this region. There remains the potential for over-estimating disease risk with the ACC/ AHA calculator when used for African or Middle Eastern patients, as has been observed in other cohorts $[28,29]$. It is critical that such risk predictions, such as the ASCVD calculations, are validated in the Africa Middle East region if they are to be used for determining eligibility for life-long medications. Validation of such 


\section{a By risk}

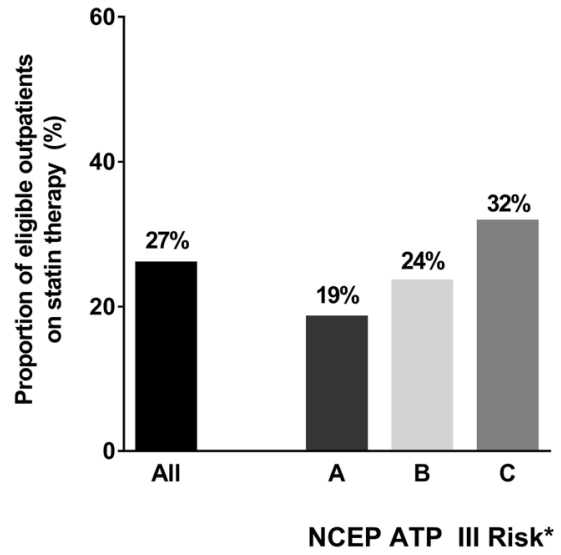

\section{c By age}

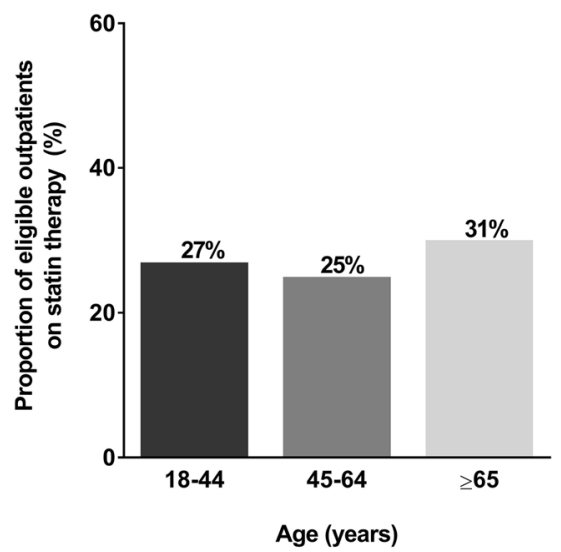

b By Gender or Community

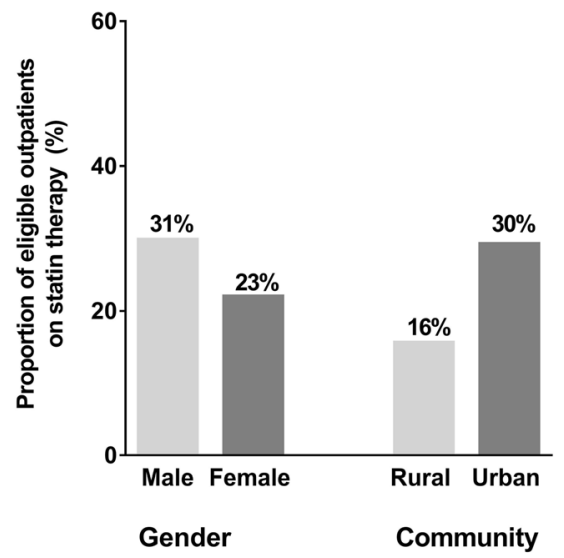

d By income

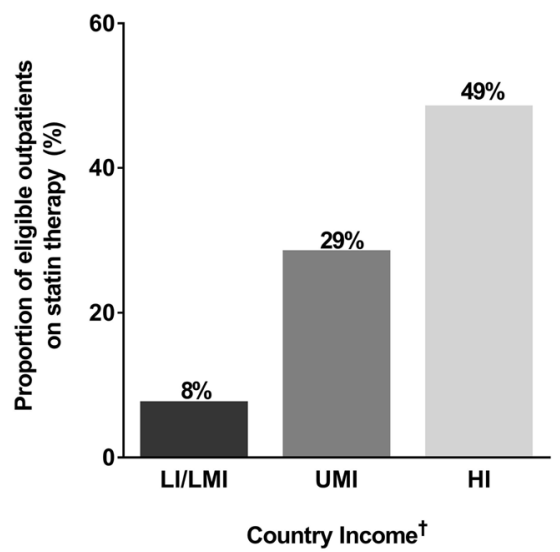

Fig. 3 Proportion of eligible outpatients prescribed statins according to the NCEP ATP III guidelines. ${ }^{*}$ NCEP ATP III indication: $\mathbf{a}, 0-1$ risk factor plus $L D L-C \geq 190 \mathrm{mg} / \mathrm{dL} ; \mathbf{b}, \geq 2$ risk factors plus $L D L-C \geq 130 \mathrm{mg} / \mathrm{dL}$; $\mathbf{c}$, coronary artery disease, transient ischemic attack, stroke, peripheral arterial disease, diabetes mellitus, and LDL-C $\geq 100 \mathrm{mg} / \mathrm{dL}$. Risk factors are listed in full in the Methods section. $\mathbf{d}+$ Country income levels: HI, high income; LI/LMI, lower/lower-middle income; UMI, upper-middle income. NCEP ATP III National Cholesterol Education Program Adult Treatment Panel III, LDL-C low-density lipoprotein cholesterol

models is limited by the paucity of well-designed regional longitudinal studies with adjudicated cardiovascular outcomes. "Risk recalibration" for every country is necessary before using these scores. Developing countries can, as an alternative solution, use the World Health Organization (WHO) chart scores adapted for every country [30]. These models have also been validated.

An equally important observation of the current study is the under-prescribing of statins among patients who were eligible based on the NCEP ATP III criteria, which was the standard of care at the time of enrollment in the ACE study. Overall, three quarters of eligible patients were not on statin therapy, including two thirds of eligible high-risk patients with prior coronary artery disease, cerebrovascular disease, peripheral arterial disease or diabetes. This was most pronounced in lower/ lower-middle income countries and rural communities where $>90$ and $>80 \%$, respectively, of eligible patients were not prescribed statins. Broadening the statin eligibility criteria with the newer guidelines together with low awareness and less education on the need for screening and treatment of dyslipidemia could further accentuate this pattern of under-prescribing among eligible outpatients in this population. Future studies are needed to identify barriers to adherence of guidelines in the Africa Middle East region, with a focus on understanding factors related to cost and access to healthcare.

The current analysis is strengthened by using a large dataset that includes outpatients from diverse countries and communities in Africa and the Middle East. Although we used standardized definitions of conventional 
risk factors, the study was limited by its cross-sectional design and reliance on single measurements. This may have affected the accuracy of our estimates, and all of our analyses should be considered descriptive in nature. Nonetheless, it is unlikely that these limitations would have differentially affected estimates from the criteria (NCEP ATP III or ACC/AHA 2013), and hence the observation of significant relative increases in eligible patients remains valid.

\section{Conclusions}

Notwithstanding differences in local approved labels, our findings show that applying the 2013 ACC/AHA cholesterol guidelines significantly increased the number of statin-eligible adults attending outpatient clinics across the Africa Middle East region, particularly in the elderly men and women (aged $\geq 65$ years), middle-aged men (aged 45-64 years), those from rural communities, and those from lower-income countries. Physicians should refer to individual product information for prescribing decisions. Further studies are needed to understand the feasibility and economic implications of these recommendations in the developing world.

\section{Abbreviations}

ACC: American College of Cardiology; AHA: American Hypertension Society; CHD: coronary heart disease; Cl: confidence interval; HDL-C: high-density lipoprotein cholesterol; LDL-C: low-density lipoprotein cholesterol

\section{Acknowledgments}

Editorial support was provided by Karen Burrows of Engage Scientific Solutions (Horsham, UK), funded by Pfizer.

\section{Funding}

The ACE study was funded by Pfizer. The sponsor was involved in the design of this sub-analysis, and in the collection, analysis, and interpretation of the data alongside the other co-authors. All authors, including the sponsor, were involved in the development of the manuscript.

\section{Availability of data and materials}

Upon request, and subject to certain criteria, conditions and exceptions (see https://www.pfizer.com/science/clinical-trials/trial-data-and-results for more information), Pfizer will provide access to individual de-identified participant data from Pfizer-sponsored global interventional clinical studies conducted for medicines, vaccines and medical devices (1) for indications that have been approved in the US and/or EU or (2) in programs that have been terminated (i.e., development for all indications has been discontinued). Pfizer will also consider requests for the protocol, data dictionary, and statistical analysis plan. Data may be requested from Pfizer trials 24 months after study completion. The de-identified participant data will be made available to researchers whose proposals meet the research criteria and other conditions, and for which an exception does not apply, via a secure portal. To gain access, data requestors must enter into a data access agreement with Pfizer.

\section{Authors' contributions}

$\mathrm{OH}, \mathrm{MIO}, \mathrm{FJR}, \mathrm{PA}, \mathrm{WMM}$, and AAA designed the study. Data analysis was led by PA, and supported by OH, MIO, FJR, WMM, and AAA. All authors $(\mathrm{OH}$, $M I O, F J R, W R, A K, M A, P A, W M M, A A A$ ) were involved in interpretation of data. Drafting of manuscript was led by $\mathrm{OH}$ and supported by MIO, FJR, WR, AK, MA, PA, WMM, and AAA. All authors $(\mathrm{OH}, \mathrm{MIO}, \mathrm{FJR}, \mathrm{WR}, \mathrm{AK}, \mathrm{MA}, \mathrm{PA}$, WMM, AAA) were involved in critical appraisal of the manuscript. All authors $(\mathrm{OH}, \mathrm{MIO}, \mathrm{FJR}, \mathrm{WR}, \mathrm{AK}, \mathrm{MA}, \mathrm{PA}, \mathrm{WMM}, \mathrm{AAA})$ read and approved the final manuscript. All authors $(\mathrm{OH}, \mathrm{MIO}, \mathrm{FJR}, \mathrm{WR}, \mathrm{AK}, \mathrm{MA}, \mathrm{PA}, \mathrm{WMM}, \mathrm{AAA})$ are accountable for all aspects of the data.

\section{Ethics approval and consent to participate}

Ethics approval was obtained from all participating centers and appropriate regulatory bodies in each country as reported elsewhere [15]: Ethics Committee, Alexandria University, Alexandria, Egypt; Research Ethics Committee, Cairo University Hospital, Cairo, Egypt; Ethics Committee for Health Care Research, Menoufiya University, Menoufiya, Egypt; Research Ethics Committee, Tanta University, Tanta, Egypt; Ghana Health Service Ethical Review Committee, Ghana Health Service, Accra, Ghana; Ethics Review Committee, Kenya Medical Research Institute, Nairobi, Kenya; Health Research Ethics Committee, University of Abuja Teaching Hospital, Abuja, Nigeria; Health Research Ethics Committee, National Hospital, Abuja, Nigeria; Research Ethics Committee, Ministry of Health, Calabar, Nigeria; Health Research Ethics Committee, University of Nigeria Teaching Hospital, Enugu, Nigeria; Ethics Committee, Saudi Hypertension Management Society, Saudi Arabia; PharmaEthics, Lyttleton Manor, South Africa; Institutional Review Board, Amman, Jordan; Joint Committee for the Protection of Human Subjects in Research, Kuwait; Commission d'ethique, CHU Notre Dame De Secours, Jbeil, Lebanon; Ethics Committee, Notre Dame du Liban Hospital, Lebanon; Ethics Committee, Monla Hospital, Tripoli, Lebanon; Ethics Committee, Najar Hospital, Beirut, Lebanon; Ethics and Research Committee, Mafraq Hospital, Abu Dhabi, UAE; Al Ain Medical District Human Research Ethics Committee, Al Ain, UAE; Medical Research Committee, Dubai Health Authority, Dubai, UAE; Research Ethics Committee, Al Qassimi Hospital, Sharjah, UAE; Unité Des Essais Cliniques, Direction de la Pharmacie, Ministère De La Santé De La Population et De La Réforme Hospitalière, République Algérienne Démocratique et Populaire; National Ethics Committee, Cameroon; Comité National d'Ethique pour la Recherche en Santé, République Du Sénégal; Le Comité d'Ethique et de Recherche, Farhat Hached Hôpital Universitaire, Sousse, Ministere De La Sante Publique, République Tunisienne.

\section{Consent for publication}

Not applicable.

\section{Competing interests}

Omar Hamoui is a member of advisory boards, and has received speaking honoraria, from Pfizer, AstraZeneca, Boehringer Ingelheim, Novartis, Servier, Eli Lilly, Takeda, Merck Sharpe \& Dohme, and Menirini. Mohamed I. Omar was a full-time employee of Pfizer when this study was conducted. Frederick J. Raal has received research grants, honoraria, or consulting fees for professional input and/or delivered lectures from AstraZeneca, Pfizer, Merck, Sanofi, Regeneron, and Amgen. Wafa Rashed declares no conflict of interest. Abdoul Kane has received research, honoraria, or consulting fees for professional input and/or delivered lectures from Servier, Pfizer, Merck, and Sanofi. Mohamed Alami declares no conflict of interest. Paula Abreu and Walid M. Mashhoud are full-time employees of Pfizer. Alawi A. Alsheikh-Ali declares no conflict of interest.

\section{Publisher's Note}

Springer Nature remains neutral with regard to jurisdictional claims in published maps and institutional affiliations.

\section{Author details}

${ }^{1}$ Cardiovascular Diseases, Clemenceau Medical Center, Beirut, Lebanon. ${ }^{2}$ Medical Department, Pfizer Gulf FZ LLC, Dubai, United Arab Emirates. ${ }^{3}$ Department of Medicine, Faculty of Health Sciences, University of the Witwatersrand, Johannesburg, South Africa. ${ }^{4}$ Cardiology Division, Mubarak Al-kabeer Hospital, Jabriya, Kuwait. ${ }^{5}$ Department of Cardiology, Dakar University, Hopital General de Grand yoff, Dakar, Senegal. ${ }^{\circ}$ Private Practice, Casablanca, Morocco. ${ }^{7}$ Pfizer Inc, New York, NY, USA. ${ }^{8}$ Pfizer Saudi Limited, Jeddah, KSA, Saudi Arabia. ${ }^{9}$ College of Medicine, Mohammed Bin Rashid University of Medicine and Health Sciences, Dubai, United Arab Emirates.

Received: 22 August 2018 Accepted: 27 February 2019

Published online: 15 March 2019

\section{References}

1. Heart Protection Study Collaboration Group. MRC/BHF heart protection study of cholesterol lowering with simvastatin in 20,536 high-risk individuals: a randomised placebo-controlled trial. Lancet. 2002;360(9326):7-22.

2. Amarenco P, Bogousslavsky J, Callahan A 3rd, Goldstein LB, Hennerici M Rudolph AE, Sillesen H, Simunovic L, Szarek M, Welch KM, et al. High-dose 
atorvastatin after stroke or transient ischemic attack. N Engl J Med. 2006;355(6):549-59.

3. Cholesterol Treatment Trialists' (CTT) Collaboration, Baigent C, Blackwell L, Emberson J, Holland LE, Reith C, Bhala N, Peto R, Barnes EH, Keech A, et al. Efficacy and safety of more intensive lowering of LDL cholesterol: a metaanalysis of data from 170,000 participants in 26 randomised trials. Lancet. 2010;376(9753):1670-81.

4. Cholesterol Treatment Trialists' (CTT) Collaborators, Mihaylova B, Emberson J, Blackwell L, Keech A, Simes J, Barnes EH, Voysey M, Gray A, Collins R, et al. The effects of lowering LDL cholesterol with statin therapy in people at low risk of vascular disease: meta-analysis of individual data from 27 randomised trials. Lancet. 2012;380(9841):581-90.

5. LaRosa JC, Grundy SM, Waters DD, Shear C, Barter P, Fruchart JC, Gotto AM, Greten H, Kastelein JJ, Shepherd J, et al. Intensive lipid lowering with atorvastatin in patients with stable coronary disease. N Engl J Med. 2005;352(14):1425-35.

6. Colhoun HM, Betteridge DJ, Durrington PN, Hitman GA, Neil HA, Livingstone SJ, Thomason MJ, Mackness MI, Charlton-Menys V, Fuller JH. Primary prevention of cardiovascular disease with atorvastatin in type 2 diabetes in the collaborative atorvastatin diabetes study (CARDS): multicentre randomised placebo-controlled trial. Lancet. 2004;364(9435):685-96.

7. Ridker PM, Danielson E, Fonseca FA, Genest J, Gotto AM Jr, Kastelein JJ, Koenig W, Libby P, Lorenzatti AJ, MacFadyen JG, et al. Rosuvastatin to prevent vascular events in men and women with elevated C-reactive protein. N Engl J Med. 2008;359(21):2195-207.

8. Sever PS, Dahlöf B, Poulter NR, Wedel H, Beevers G, Caulfield M, Collins R, Kjeldsen SE, Kristinsson A, Mclnnes GT, et al. Prevention of coronary and stroke events with atorvastatin in hypertensive patients who have average or lower-than-average cholesterol concentrations, in the AngloScandinavian cardiac outcomes trial-lipid lowering arm (ASCOT-LLA): a multicentre randomised controlled trial. Lancet. 2003;361(9364):1149-58.

9. Minder CM, Blaha MJ, Horne A, Michos ED, Kaul S, Blumenthal RS. Evidencebased use of statins for primary prevention of cardiovascular disease. Am J Med. 2012;125(5):440-6.

10. Collins R, Reith C, Emberson J, Armitage J, Baigent C, Blackwell L, Blumenthal R, Danesh J, Smith GD, DeMets D, et al. Interpretation of the evidence for the efficacy and safety of statin therapy. Lancet. 2016; 388(10059):2532-61.

11. Yusuf S, Rangarajan S, Teo K, Islam S, Li W, Liu L, Bo J, Lou Q, Lu F, Liu T, et al. Cardiovascular risk and events in 17 low-, middle-, and high-income countries. N Engl J Med. 2014;371(9):818-27.

12. Gehani AA, Al-Hinai AT, Zubaid M, Almahmeed W, Hasani MR, Yusufali AH, Hassan MO, Lewis BS, Islam S, Rangarajan S, et al. Association of risk factors with acute myocardial infarction in Middle Eastern countries: the INTERHEART Middle East study. Eur J Prev Cardiol. 2014;21(4):400-10.

13. Yusuf S, Reddy S, Ounpuu S, Anand S. Global burden of cardiovascular diseases: part I: general considerations, the epidemiologic transition, risk factors, and impact of urbanization. Circulation. 2001;104(22):2746-53.

14. Reda A, Abdel-Rehim AA, Etman A, Afifi OS. Centralized pan-Middle East survey on the under-treatment of hypercholesterolemia: results from the CEPHEUS study in Egypt. Cardiol Ther. 2014;3(1-2):27-40.

15. Alsheikh-Ali AA, Omar MI, Raal FJ, Rashed W, Hamoui O, Kane A, Alami M, Abreu P, Mashhoud WM. Cardiovascular risk factor burden in Africa and the Middle East: the Africa Middle East cardiovascular epidemiological (ACE) study. PLoS One. 2014;9(8):e102830.

16. Steyn K, Sliwa K, Hawken S, Commerford P, Onen C, Damasceno A, Ounpuu S, Yusuf S. Risk factors associated with myocardial infarction in Africa: the INTERHEART Africa study. Circulation. 2005;112(23):3554-61.

17. Steyn K, Levitt NS, Hoffman M, Marais AD, Fourie JM, Lambert EV, Gaziano TA, Kepe L, Lombard CJ. The global cardiovascular diseases risk pattern in a peri-urban working-class community in South Africa. The Mamre study. Ethn Dis. 2004;14(2):233-42.

18. American Diabetes Association. Diagnosis, management and prevention of the common dyslipidaemias in South Africa-clinical guideline, 2000. South African Medical Association and Lipid and Atherosclerosis Society of Southern Africa Working Group. S Afr Med J 2000, 90(2 Pt 2):164-174.

19. Stone NJ, Robinson JG, Lichtenstein AH, Bairey Merz CN, Blum CB, Eckel RH, Goldberg AC, Gordon D, Levy D, Lloyd-Jones DM, et al. 2013 ACC/AHA guideline on the treatment of blood cholesterol to reduce atherosclerotic cardiovascular risk in adults: a report of the American College of Cardiology/
American Heart Association task force on practice guidelines. J Am Coll Cardiol. 2014:63(25 Pt B):2889-934.

20. National Cholesterol Education Program. Third report of the National Cholesterol Education Program (NCEP) expert panel on detection, evaluation, and treatment of high blood cholesterol in adults (adult treatment panel III) final report. Circulation. 2002;106(25):3143-421.

21. Graham I, Atar D, Borch-Johnsen K, Boysen G, Burell G, Cifkova R, Dallongeville J, De Backer G, Ebrahim S, Gjelsvik B, et al. European guidelines on cardiovascular disease prevention in clinical practice: full text. Fourth Joint Task Force of the European Society of Cardiology and other societies on cardiovascular disease prevention in clinical practice (constituted by representatives of nine societies and by invited experts). Eur J Cardiovasc Prev Rehabil. 2007;14(Suppl 2):S1-113.

22. American Diabetes Association. Diagnosis and classification of diabetes mellitus. Diabetes Care. 2010;33(Suppl 1):S62-9.

23. World Bank Country Classifications [https://datahelpdesk.worldbank.org/ knowledgebase/articles/906519].

24. Teo K, Chow CK, Vaz M, Rangarajan S, Yusuf S. The prospective urban rural epidemiology (PURE) study: examining the impact of societal influences on chronic noncommunicable diseases in low-, middle-, and high-income countries. Am Heart J. 2009;158(1):1-7 e1.

25. Taylor F, Huffman MD, Macedo AF, Moore TH, Burke M, Davey Smith G, Ward K, Ebrahim S. Statins for the primary prevention of cardiovascular disease. Cochrane Database Syst Rev. 2013;1:CD004816.

26. Chou R, Dana T, Blazina I, Daeges M, Jeanne TL. Statins for prevention of cardiovascular disease in adults: evidence report and systematic review for the US preventive services task force. JAMA. 2016;316(19):2008-24.

27. Roth GA, Forouzanfar MH, Moran AE, Barber R, Nguyen G, Feigin VL, Naghavi M, Mensah GA, Murray CJ. Demographic and epidemiologic drivers of global cardiovascular mortality. N Engl J Med. 2015;372(14):1333-41.

28. Chia YC, Lim HM, Ching SM. Does use of pooled cohort risk score overestimate the use of statin?: a retrospective cohort study in a primary care setting. BMC Fam Pract. 2014;15:172.

29. Echeverria G, Dussaillant C, Villarroel L, Rigotti A. Increased statin eligibility based on ACC/AHA versus NCEP guidelines for high cholesterol management in Chile. J Clin Lipidol. 2016;10(1):192-8 e191.

30. WHO/ISH cardiovascular risk prediction charts [http://www.who.int/ cardiovascular_diseases/guidelines/Chart_predictions/en/].

Ready to submit your research? Choose BMC and benefit from:

- fast, convenient online submission

- thorough peer review by experienced researchers in your field

- rapid publication on acceptance

- support for research data, including large and complex data types

- gold Open Access which fosters wider collaboration and increased citations

- maximum visibility for your research: over $100 \mathrm{M}$ website views per year

At BMC, research is always in progress.

Learn more biomedcentral.com/submissions 